\title{
Antimicrobial activity of a combination of three natural plant extracts and development of a herbal soap
}

\author{
Nirupama Wijayawardhana ${ }^{1}$, Dhanushi Cooray ${ }^{1}$, Banukie Jayasuriya ${ }^{1 *}$ \\ Inoka Uluwaduge², Farah Meedin ${ }^{3}$, Menuka Arawwawala ${ }^{4}$ \\ 1 Department of Pharmacy and Pharmaceutical Sciences, Faculty of Allied Health Sciences, University of Sri Jayewardenepura, Nugegoda, Sri Lanka \\ 2 Department of Basic Sciences, Faculty of Allied Health Sciences, University of Sri Jayewardenepura, Nugegoda, Sri Lanka \\ 3 Department of Medical Laboratory Sciences, Faculty of Allied Health Sciences, University of Sri Jayewardenepura, Nugegoda, Sri Lanka \\ 4 Industrial Technology Institute, Colombo 07, Sri Lanka
}

\begin{abstract}
Azadirachta indica, Cassia fistula and Nelumbo nucifera are medicinal plants that are frequently found in Sri Lanka. Although the antimicrobial activity of these plants has been investigated individually, the effectiveness of a combined extract has not been determined in previous studies. This study aimed to evaluate the antimicrobial activity of $A$. indica, C. fistula, $N$. nucifera and their combined extract to formulate an antimicrobial herbal soap. Different concentrations of aqueous and ethanol extracts of powdered leaves of $A$. indica, C. fistula and flowers of $N$. nucifera were prepared separately. Each extract was tested against Staphylococcus aureus, Pseudomonas aeruginosa and Candida albicans using the agar well diffusion method. Combined extract was prepared using selected extracts of each plant with the highest antimicrobial activity. Combined extract formulated from ethanol extract of $C$. fistula and aqueous extracts of $A$. indica and $N$. nucifera was incorporated into a herbal soap. The antimicrobial activity of the combined extract and the herbal soap was determined using the agar well diffusion method. Combined extract and formulated soap exhibited antimicrobial activity against tested organisms with the highest activity against $S$. aureus. The physical and chemical parameters of the formulated herbal soap were determined. The $\mathrm{pH}$ of the formulated soap at $28^{\circ} \mathrm{C}$ was 9.11 , the percentage of alcohol insoluble matter and free alkali were $24.6 \%$ and $1.6 \%$ respectively, which were within the accepted range. In conclusion, compared to the results of individual extracts, the soap has demonstrated enhanced antimicrobial activity against tested organisms. Further development of herbal soap as a value added product would be beneficial.
\end{abstract}

\section{Keywords:}

Azadirachta indica, Antimicrobial activity, Cassia fistula, Combined extract, Herbal soap, Nelumbo nucifera

\section{INTRODUCTION}

Medicinal plants have been used in traditional medicine predominantly in Asian countries and they are considered as the root of traditional medicine. Many recent research studies showed that most of the medicinal plants possess diverse biological activities such as antibacterial, antifungal, antiviral, antioxidant and antiinflammatory effects, etc ${ }^{1}$. As one of the best sources of obtaining antimicrobial agents, medicinal plants are gaining attention in the present world today. That is mainly due to increased resistance to synthetic compounds, inexpensive, fewer side effects compared to synthetic compounds and availability. Recent studies have revealed that natural constituents of higher plants include new sources of antimicrobial agents ${ }^{2}$. Plants possess antimicrobial properties due to their secondary metabolites. Tannins, flavonoids, phenolic compounds and alkaloids have demonstrated in vitro antimicrobial activity $^{3}$.

Sri Lanka has a diverse medicinal plant system. Medicinal herbs used in Ayurveda medicine are reported to possess antimicrobial activity. According to Hewage et al., ${ }^{4}$ in Sri Lanka, there are about 3300 flowering plants in which 830 species (25\%) are endemic to Sri Lanka.

There are a vast number of conditions that can

\section{*Corresponding author:}

*Banukie Jayasuriya banukie@sjp.ac.lk 
affect skin diseases. Skin infections are of several types that differ from the type of pathogen which causing infection such as fungal infections and bacterial infections ${ }^{5}$. Recently there is a surge of using various antiseptics, including commercially available synthetic soaps and alcohol based sanitizers. Even though these formulations reduce the transmission of contagious diseases, these are produced on a large scale with harsh chemicals, synthetic ingredients such as parabens, phthalates, petrochemicals, cheap fragrance oils and artificial colors all of which may lead to skin irritation and resistance among pathogens. Hence there is an urgent need to develop herbal soaps and other disinfectants and evaluate their efficacy.

Cassia fistula belongs to the family of Fabaceae and is commonly known as a golden shower plant. It has greenish-grey bark and has compound leaves. The conspicuous feature of this plant is golden yellow color hanging flower bunches about $40 \mathrm{~cm}$ in length ${ }^{6}$. Recent research findings have demonstrated that $C$. fistula possesses antioxidant, anti-mutagenic, antitumor, antimicrobial and anti-inflammatory activities ${ }^{7}$. C. fistula consists of various constituents such as flavonoids, phenols and proanthocyanidins. The bark, leaves and flowers of the plant were evaluated for potential constituents with antimicrobial activity ${ }^{7}, C$. fistula is considered as one of the abundantly used medicinal plants in Unani and Ayurvedic medical systems. Fruit pulp, bark, flowers, pods, leaves and roots of the plant are used ${ }^{8}$. Preparations like infusions, decoctions or powders which are either alone or in combination with other medicinal plants are used in traditional medicine? Mainly the tender leaves are used as a purgative while the older ones together with the bark are ground into a paste and applied during ringworm infections, insect bites, rheumatism, facial paralysis, leprosy, chronic eczema and psoriasis ${ }^{10}$. In traditional system of medicine, the plant is used against skin diseases, diabetes, haematemesis, worm and microbial infections, abdominal diseases, abdominal tumours, heart diseases, during retention of urine, abdominal colic, heamostatic, due to its antipyretic and analgesic nature and to reduce oedema and prevent burning sensation ${ }^{8,11}$. Chakramardha tailamu, is a compound ayurvedic oil prepared using $C$. fistula which is beneficial in eczema, ringworm and other skin diseases. The plant is used in preparations such as Maha-marichayadi taila, aragvadhadi-kwatha etc ${ }^{9}$.

Azadirachta indica, which is often known as

Neem, belongs to the family of Meliaceae. Leaves of the plant are compound and each carry 5-15 leaflets. According to several studies conducted, it has been demonstrated that different plant parts of $A$. indica possess diverse medicinal properties such as antibacterial, antifungal, antiviral, anti-oxidant, anti-malarial, etc $^{12}$. Azadirachtin, nimbin, nimbidol and nimbolinin are important compounds that have been isolated from the plant ${ }^{13}$. Mahmoodin, margolone, mergolonone and isomargolonone which have been isolated from $A$. indica show antibacterial activity whereas cyclic trisulphide and cyclic tetrasulphides show antifungal activity $^{14}$. The plant is used in Ayurveda, Unani and homeopathy for the treatment of many infectious, metabolic or cancer diseases 9 . The leaves are bitter, astringent, acrid, depurative, demulcent and refrigerant $^{15}$. A strong decoction of the fresh leaves has antiseptic properties and is used for cleaning wounds, ulcers and leprosy ${ }^{16}$. Leaves poultice is used for boils and sores treatment whereas the infusion is reported to be used in the treatment of malarial and intermittent fevers. Leaf juice is given in worms, jaundice and skin diseases ${ }^{11,16,17}$. In Sri Lanka, the juice of the fresh leaves is given with rock salt for intestinal worms and with honey for jaundice and skin diseases ${ }^{10}$. The leaf paste has been used externally for small pox treatments whereas the tincture is applied locally to treat bruises and sprains. Leaf ash mixed with ghee is useful in psoriasis ${ }^{16}$. Moreover, A. indica is useful in leucoderma, pruritus, ophthalmopathy, dyspepsia, tuberculosis, burning sensation and eczema and exhibits wound healing properties ${ }^{11,15}$.

Nelumbo nucifera is an aquatic plant, belonging to the family of Nelumbonaceae. This is a rhizomatous plant consisting of a creeping, elongated stem with nodal roots. It is having cup-shaped aerial leaves and flat-shaped floating leaves. The colour of the flower varies from white to reddish-pink and has a pleasant fragrance. The flower of $N$. nucifera demonstrated hypoglycemic, antipyretic, antioxidant, antimicrobial and antihypertensive abilities. Furthermore, it also acts as anti acne due to its antibacterial properties ${ }^{17}$. A variety of chemical constituents with different therapeutic activities were isolated from the flowers of N.nucifera ${ }^{18}$. The flower is used in Ayurveda, Siddha, Unani and other medicinal systems ${ }^{9}$ and reported to be astringent refrigerant and cardiotonic ${ }^{14}$. The stamens of the flowers are used for bleeding piles and debility and weakness in children ${ }^{10}$. Flowers with stamens and juice of the flower stalk are used for diarrhea, cholera, fever, liver complaints and gastric ulcers in Ayurveda ${ }^{10}$. The dose of the flower extract used in decoctions is $12-24 \mathrm{~g}$ and has been claimed in the treatment of skin diseases ${ }^{9,11}$. Syrup made from flower is recommended for coughs, dysentery and haemorrhages and the ground petals are assumed to be effective in rectifying syphilis in Malaya ${ }^{10}$. A scanty literature was available on formulation of herbal soaps and evaluating their antimicrobial activity.

Moreover, the available literature did not support evidences on any herbal formulations based on combined extracts of $C$. fistula, A. indica and $N$. nucifera. Therefore, the purpose of this study was to formulate a herbal soap using the extracts of $C$. fistula, A. indica and $N$. nucifera and to investigate the antimicrobial activity 
of the combined extract and the herbal soap against common microorganisms. Furthermore, this study was aimed to evaluate the physicochemical parameters of the prepared herbal formulation.

\section{MATERIALS AND METHODS}

\subsection{Study setting}

The study was conducted at the Department of Pharmacy and Pharmaceutical Sciences and Department of Medical Laboratory Sciences, Faculty of Allied Health Sciences, University of Sri Jayewardenepura, Sri Lanka and Industrial Technology Institute, Colombo 07, Sri Lanka.

\subsection{Collection of plant materials and authentication}

Fresh leaves of $A$. indica, white flowers of $N$. nucifera, and fresh leaves of $C$. fistula were collected from Southern Province and Western Province, Sri Lanka. Plants were authenticated at the National Herbarium, Botanical Gardens, Peradeniya, Sri Lanka and the voucher specimens were deposited under reference numbers, A Z Pharm .01 (A. indica), N N Pharm .01 ( $N$. nucifera) and C F Pharm .01 (C. fistula).

\subsection{Preparation of extracts}

The collected plant parts (leaves and flowers) were washed, air dried for three days and dried in a hot air oven at $40^{\circ} \mathrm{C}$ until constant weight was obtained and powdered to a coarse powder, and stored in air tight bottles for the studies. A sample $(50 \mathrm{~g})$ of each plant was added to a round bottom flask containing $150 \mathrm{ml}$ of ethanol or distilled water and boiled for four hours. Then the extract was filtered and the filtrate was concentrated using a rotary evaporator. Water extract was freezedried. The extracts were stored at $4^{\circ} \mathrm{C}$ until used ${ }^{19}$.

\subsection{Determination of antimicrobial activity of selected plant extracts}

The antimicrobial activities of the selected plant extracts were determined by the agar well diffusion method $^{20}$. Isolates of Candida albicans, Staphylococcus aureus ATCC 25923 and Pseudomonas aeruginosa ATCC 27853 were obtained from the Department of Microbiology, Faculty of Medical Sciences, University of Sri Jayewardenepura. Subcultured organisms were used to prepare microbial suspensions. The turbidity of the suspensions was adjusted to $0.5 \mathrm{McF}$ arland standard $\left(1 \times 10^{8} \mathrm{CFU} / \mathrm{ml}\right.$ inoculum). The prepared inoculum was streaked by using a sterile cotton swab on the surface of Mueller Hinton Agar (MHA) using the spread plate method. Then the plates were allowed to dry for $5 \mathrm{~min}$.
Wells were cut by using a sterile dropper with a $6 \mathrm{~mm}$ diameter. A drop of molten agar was added to each well to seal the bottom of the well. Stock solutions were prepared for each extract with a concentration of 1000 $\mathrm{mg} / \mathrm{ml}$ in $1 \%$ dimethyl sulphoxide (DMSO). Each stock solution was diluted using $1 \%$ DMSO and a concentration series ranging from $31.25-1000 \mathrm{mg} / \mathrm{ml}$ was prepared. From each concentration, 50 $\mu \mathrm{l}$ were added to the wells.

Bacterial cultures and fungal cultures were incubated at $37^{\circ} \mathrm{C}$ for $24 \mathrm{hrs}$. and $48 \mathrm{hrs}$. respectively. $0.03 \%$ of gentamycin and $1 \%$ of clotrimazole were used as a positive control for bacteria and fungi respectively, and $1 \%$ DMSO was used as the negative control. Each concentration includes triplicates. Antimicrobial activity was determined by measuring the diameter of the zone of inhibition around the well against each microorganism $^{20,21}$.

2.5. Determination of the effective extract of each plant and effective concentration of selected plant extracts against tested microorganisms to formulate a combined extract

According to the results of the antimicrobial activity of each extract of the three plants, dose-response curves were graphed separately. The suitable types of extracts were selected from each dose-response curve by considering the $\mathrm{IC}_{50}$ value of each plant extract to incorporate into the combined extract. Effective concentrations of extracts selected were determined. Doseresponse curves of selected plant extracts were graphed separately against each microorganism tested. Effective concentrations were selected at the highest point of the linear range. A common effective concentration for all tested organisms was selected from the linear range of the graph.

\subsection{Formulation of herbal soap using the combined extract}

Glycerin soap base was weighed and melted in a water bath. Previously determined concentrations of plant extracts were prepared by dissolving the relevant solvents (Assuming that the active ingredient should be about 5\% of the total weight of soap). The plant extracts were added to the melted soap base. Stearic acid was dissolved in a small amount of hot water and added to the mixture. As the fragrance enhancer, the volatile oil of $N$. nucifera was added. The ultimate mixture was stirred using a magnetic stirrer. The melted mixture was poured into separate moulds and left until solidified ${ }^{22}$.

\subsection{Determination of the antimicrobial activity of the combined plant extract and formulated herbal soap}

The antimicrobial activity of the combined 
extract was determined by the agar well diffusion method $^{20}$. According to the proportions determined, the selected concentration of each plant extract was introduced into the wells of the agar plates that were previously streaked with $S$. aureus, $P$. aeruginosa and C. albicans. A percentage of $0.03 \%$ gentamycin and $1 \%$ clotrimazole were used as the positive control for bacteria and fungi respectively. $1 \%$ DMSO was used as the negative control. The plates were incubated at $37^{\circ} \mathrm{C}$ for $24 \mathrm{hrs}$. (48 hrs. for fungi) and the diameters of the zone of inhibition were measured. Six concentrations of formulated soap were prepared by dissolving it in $1 \%$ DMSO. Antimicrobial activity of each solution was tested by agar well diffusion method ${ }^{22}$.

\subsection{Evaluation of physicochemical parameters of the formulated herbal soap}

\subsubsection{Physical characteristics}

Odour, colour and appearance of the formulated soap were observed ${ }^{22}$.

\subsubsection{Determination of $p H$}

Formulated soap was dissolved in $100 \mathrm{ml}$ of distilled water and stored for 2 hours. Then $\mathrm{pH}$ was measured by a calibrated $\mathrm{pH}$ meter ${ }^{22}$.

\subsubsection{Determination of percentage free alkali}

Formulated soap ( $5 \mathrm{~g}$ ) was dissolved in $50 \mathrm{ml}$ of neutralized alcohol. The mixture was refluxed for 30 minutes. The resulted mixture was cooled and titrated with $0.1 \mathrm{~N} \mathrm{HCl}$ using phenolphthalein as the indicator ${ }^{22}$.

\subsubsection{Foam height}

Formulated soap $(0.5 \mathrm{~g})$ was dissolved in $25 \mathrm{ml}$ of distilled water and it was transferred into a $100 \mathrm{ml}$ measuring cylinder. Volume of soap mixture was made up to $50 \mathrm{ml}$ with water. Then the cylinder was shaken 25 times and allowed to stand until the aqueous volume makes up to $50 \mathrm{ml}$. Finally, the height of the foam was measured above the $50 \mathrm{ml}$ mark of the measuring cylinder ${ }^{22}$.

\subsubsection{Foam retention}

Formulated soap solution (1\%) was prepared by dissolving the soap in distilled water. A volume of 25 $\mathrm{ml}$ of soap mixture was placed in a $100 \mathrm{ml}$ measuring cylinder and shaken it for 10 times. The volume of foam was recorded for $10 \mathrm{~min}$ at 1 -min intervals ${ }^{22}$.

\subsubsection{Alcohol insoluble matter}

Formulated soap $(5 \mathrm{~g})$ was dissolved in $50 \mathrm{ml}$ of warm ethanol vigorously. The resulting solution was filtered through a tarred filter paper with $20 \mathrm{ml}$ of additional warm ethanol. Then the filter paper was kept in the oven for 1 hour at $105^{\circ} \mathrm{C}$. Finally, the weight of the residue was weighed ${ }^{22}$.

\subsubsection{Moisture / Volatile matter}

Formulated soap ( $5 \mathrm{~g}$ ) was placed in an oven for $2 \mathrm{hrs}$ at a temperature of $105^{\circ} \mathrm{C}$ and repeated until a constant weight was obtained and the $\%$ moisture was calculated ${ }^{22}$.

\subsection{Statistical analysis}

The data were presented as mean $\pm \mathrm{SD}$ (Standard Deviation) of three replicates. One-way analysis of variance (ANOVA) was performed by using IBM SPSS Statistics 25.0 software to determine significant group differences and means were considered as statistically significant if $p<0.05$.

\section{RESULTS}

\subsection{Determination of the zones of inhibition of different concentrations of $C$. fistula leaf extracts against selected microorganisms}

Table 1. Diameter of the zones of inhibition of different concentrations of leaf extracts of $C$. fistula against selected microorganisms.

\begin{tabular}{|c|c|c|c|c|c|c|}
\hline \multirow{3}{*}{$\begin{array}{l}\text { Concentration of } C \text {. fistula leaf extract } \\
(\mathrm{mg} / \mathrm{ml})\end{array}$} & \multicolumn{6}{|c|}{ The diameter of zone of inhibition (mm) of leaf extracts of C.fistula } \\
\hline & \multicolumn{3}{|c|}{ Ethanol extract } & \multicolumn{3}{|c|}{ Aqueous extract } \\
\hline & S.aureus & P.aeruginosa & C. albicans & S. aureus & P.aeruginosa & C. albicans \\
\hline 1000 & $21.0 \pm 0.7^{*}$ & $10.0 \pm 0.5^{*}$ & $0.0 \pm 0.0$ & $18.0 \pm 0.7^{*}$ & $12.0 \pm 0.5^{*}$ & $0.0 \pm 0.0$ \\
\hline 500 & $18.0 \pm 0.7^{*}$ & $8.0 \pm 0.5^{*}$ & $0.0 \pm 0.0$ & $16.0 \pm 0.7^{*}$ & $7.0 \pm 0.5^{*}$ & $0.0 \pm 0.0$ \\
\hline 250 & $15.0 \pm 0.7^{*}$ & $0.0 \pm 0.0$ & $0.0 \pm 0.0$ & $11.0 \pm 0.7^{*}$ & $0.0 \pm 0.0$ & $0.0 \pm 0.0$ \\
\hline 125 & $13.0 \pm 0.7^{*}$ & $0.0 \pm 0.0$ & $0.0 \pm 0.0$ & $9.0 \pm 0.7^{*}$ & $0.0 \pm 0.0$ & $0.0 \pm 0.0$ \\
\hline 62.5 & $9.0 \pm 0.7^{*}$ & $0.0 \pm 0.0$ & $0.0 \pm 0.0$ & $0.0 \pm 0.0$ & $0.0 \pm 0.0$ & $0.0 \pm 0.0$ \\
\hline 31.25 & $0.0 \pm 0.0$ & $0.0 \pm 0.0$ & $0.0 \pm 0.0$ & $0.0 \pm 0.0$ & $0.0 \pm 0.0$ & $0.0 \pm 0.0$ \\
\hline Positive control & $37.0 \pm 1.7^{*}$ & $32.0 \pm 1.7^{*}$ & $25.0 \pm 1.7^{*}$ & $33.0 \pm 1.7^{*}$ & $31.0 \pm 1.7^{*}$ & $31.0 \pm 1.7^{*}$ \\
\hline Negative control & $0.0 \pm 0.0$ & $0.0 \pm 0.0$ & $0.0 \pm 0.0$ & $0.0 \pm 0.0$ & $0.0 \pm 0.0$ & $0.0 \pm 0.0$ \\
\hline
\end{tabular}

Data presented as Mean \pm SD

${ }^{*}$ Significant when compared with the negative control; $p<0.05$ 
Table 2. Diameters of the zone of inhibition of different concentrations of white flower extracts of $N$. nucifera against selected microorganisms.

\begin{tabular}{|c|c|c|c|c|c|c|}
\hline \multirow{3}{*}{$\begin{array}{l}\text { Concentration } \\
(\mathrm{mg} / \mathrm{ml}) \text { of } N \text {. nucifera flower extract }\end{array}$} & \multicolumn{6}{|c|}{ The diameter of zone of inhibition $(\mathrm{mm})$ of white flower extracts of $N$. nucifera } \\
\hline & \multicolumn{3}{|c|}{ Ethanol extract } & \multicolumn{3}{|c|}{ Aqueous extract } \\
\hline & S.aureus & P.aeruginosa & C. albicans & S. aureus & P.aeruginosa & C. albicans \\
\hline 1000 & $19.0 \pm 0.5^{*}$ & $10.0 \pm 0.3^{*}$ & $0.0 \pm 0.0$ & $20.0 \pm 0.5^{*}$ & $10.0 \pm 0.3^{*}$ & $10.0 \pm 0.3^{*}$ \\
\hline 500 & $8.0 \pm 0.5^{*}$ & $9.0 \pm 0.3^{*}$ & $0.0 \pm 0.0$ & $10.0 \pm 0.5^{*}$ & $7.0 \pm 0.3^{*}$ & $8.0 \pm 0.3^{*}$ \\
\hline 250 & $12.0 \pm 0.5^{*}$ & $7.0 \pm 0.3^{*}$ & $0.0 \pm 0.0$ & $16.0 \pm 0.5^{*}$ & $0.0 \pm 0.0$ & $7.0 \pm 0.3^{*}$ \\
\hline 125 & $8.0 \pm 0.5^{*}$ & $0.0 \pm 0.0$ & $0.0 \pm 0.0$ & $15.0 \pm 0.5^{*}$ & $0.0 \pm 0.0$ & $0.0 \pm 0.0$ \\
\hline 62.5 & $0.0 \pm 0.0$ & $0.0 \pm 0.0$ & $0.0 \pm 0.0$ & $7.0 \pm 0.5^{*}$ & $0.0 \pm 0.0$ & $0.0 \pm 0.0$ \\
\hline 31.25 & $0.0 \pm 0.0$ & $0.0 \pm 0.0$ & $0.0 \pm 0.0$ & $0.0 \pm 0.0$ & $0.0 \pm 0.0$ & $0.0 \pm 0.0$ \\
\hline Positive control & $31.0 \pm 0.5^{*}$ & $31.0 \pm 0.3^{*}$ & $25.0 \pm 0.3^{*}$ & $30.0 \pm 0.5^{*}$ & $30.0 \pm 0.3^{*}$ & $31.0 \pm 0.3^{*}$ \\
\hline Negative control & $0.0 \pm 0.0$ & $0.0 \pm 0.0$ & $0.0 \pm 0.0$ & $0.0 \pm 0.0$ & $0.0 \pm 0.0$ & $0.0 \pm 0.0$ \\
\hline
\end{tabular}

Data presented as Mean \pm SD

${ }^{*}$ Significant when compared with the negative control; $p<0.05$

Table 3. Diameters of the zone of inhibition of different concentrations of leaf extracts of $A$. indica against selected microorganisms.

\begin{tabular}{|c|c|c|c|c|c|c|}
\hline \multirow{3}{*}{$\begin{array}{l}\text { Concentration } \\
(\mathrm{mg} / \mathrm{ml}) \text { of } A \text {. indica leaf extracts }\end{array}$} & \multicolumn{6}{|c|}{ The diameter of zone of inhibition $(\mathrm{mm})$ of leaf extracts of $A$. indica } \\
\hline & \multicolumn{3}{|c|}{ Ethanol extract } & \multicolumn{3}{|c|}{ Aqueous extract } \\
\hline & S.aureus & P.aeruginosa & C. albicans & S. aureus & P.aeruginosa & C. albicans \\
\hline 1000 & $16.0 \pm 0.5^{*}$ & $0.0 \pm 0.0$ & $0.0 \pm 0.0$ & $21.0 \pm 0.5^{*}$ & $0.0 \pm 0.0$ & $0.0 \pm 0.0$ \\
\hline 500 & $13.0 \pm 0.5^{*}$ & $0.0 \pm 0.0$ & $0.0 \pm 0.0$ & $18.0 \pm 0.5^{*}$ & $0.0 \pm 0.0$ & $0.0 \pm 0.0$ \\
\hline 250 & $12.0 \pm 0.5^{*}$ & $0.0 \pm 0.0$ & $0.0 \pm 0.0$ & $15.0 \pm 0.5^{*}$ & $0.0 \pm 0.0$ & $0.0 \pm 0.0$ \\
\hline 125 & $8.0 \pm 0.5^{*}$ & $0.0 \pm 0.0$ & $0.0 \pm 0.0$ & $13.0 \pm 0.5^{*}$ & $0.0 \pm 0.0$ & $0.0 \pm 0.0$ \\
\hline 62.5 & $7.0 \pm 0.5^{*}$ & $0.0 \pm 0.0$ & $0.0 \pm 0.0$ & $9.0 \pm 0.5^{*}$ & $0.0 \pm 0.0$ & $0.0 \pm 0.0$ \\
\hline 31.25 & $0.0 \pm 0.0$ & $0.0 \pm 0.0$ & $0.0 \pm 0.0$ & $0.0 \pm 0.0$ & $0.0 \pm 0.0$ & $0.0 \pm 0.0$ \\
\hline Positive control & $34.0 \pm 0.5^{*}$ & $32.0 \pm 0.3^{*}$ & $25.0 \pm 0.3^{*}$ & $31.0 \pm 0.5^{*}$ & $30.0 \pm 0.3^{*}$ & $25.0 \pm 0.3$ \\
\hline Negative control & $0.0 \pm 0.0$ & $0.0 \pm 0.0$ & $0.0 \pm 0.0$ & $0.0 \pm 0.0$ & $0.0 \pm 0.0$ & $0.0 \pm 0.0$ \\
\hline
\end{tabular}

Data presented as Mean \pm SD

*Significant when compared with the negative control; $p<0.05$

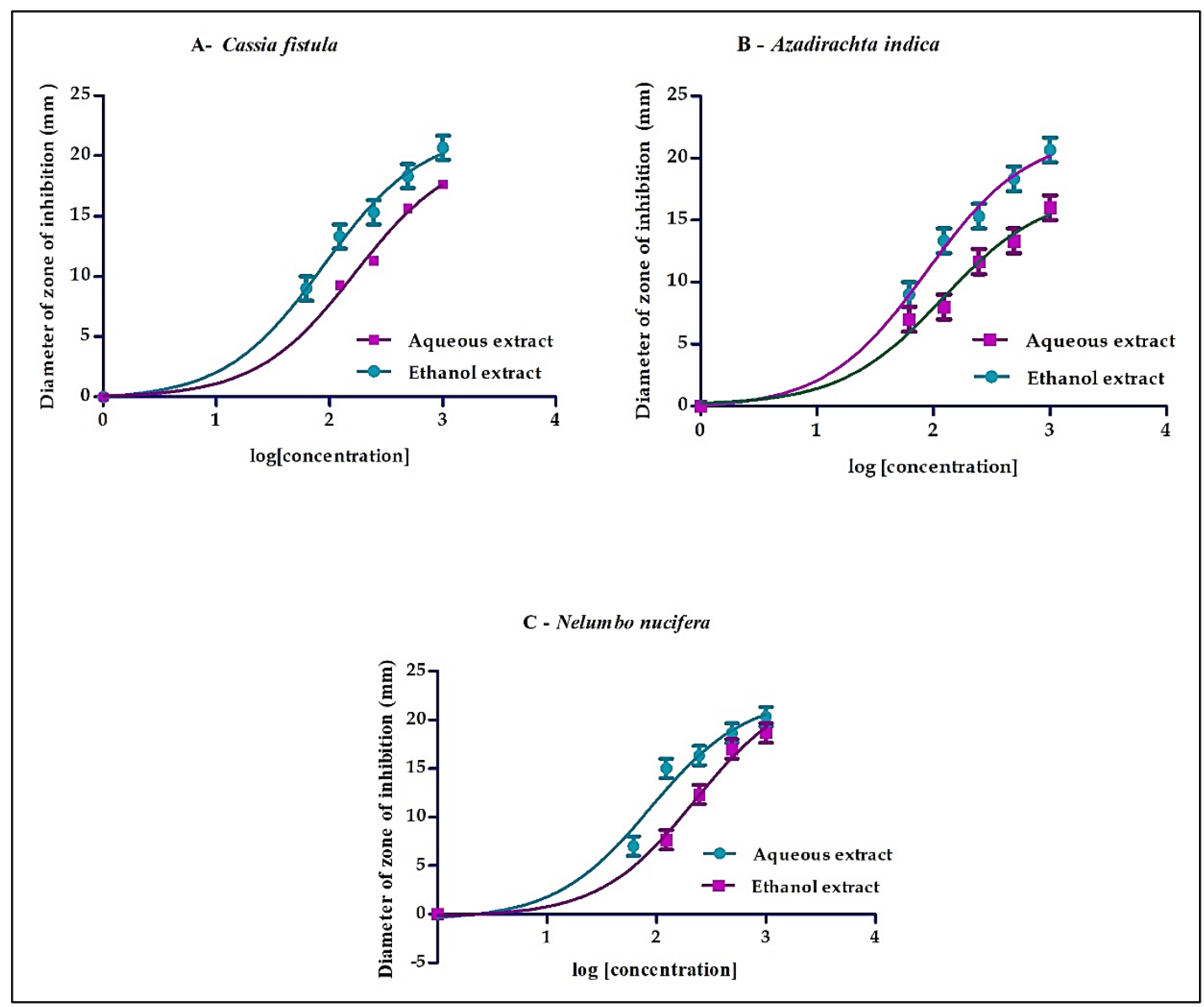

Figure 1. Dose-response curves of ethanol and aqueous extracts of $C$. fistula, A. indica and N. nucifera against S. aureus. A: C. fistula, B: A. indica and $\mathrm{C}:$ N. nucifera. 


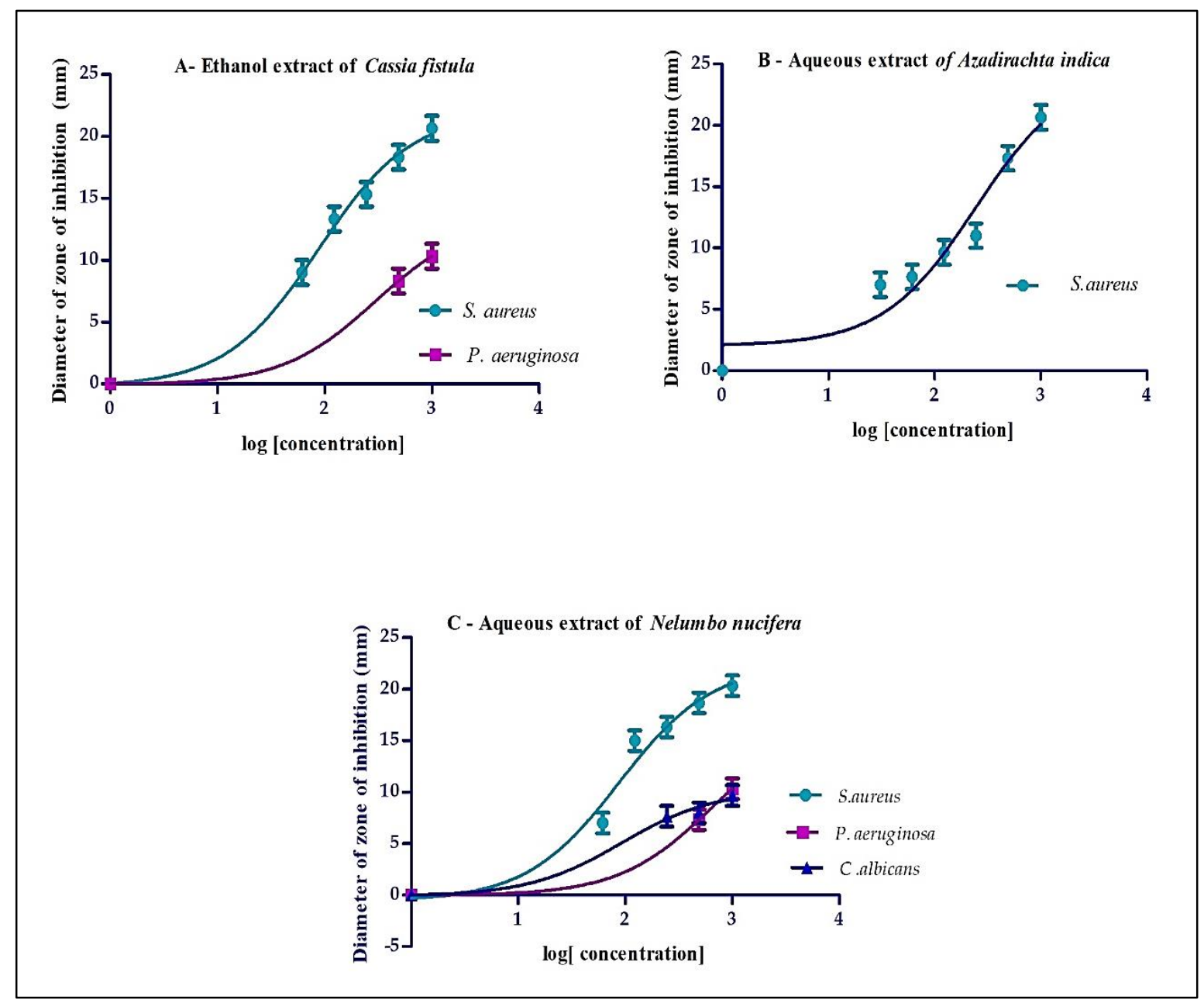

Figure 2. Dose-response curves of ethanol extract of $C$. fistula, aqueous extract of $A$. indica and aqueous extract of $N$. nucifera against tested organisms.

A: Ethanol extract of $C$. fistula against $S$. aureus and $P$. aeruginosa

B: Aqueous extract of $A$. indica against $S$. aureus

C: Aqueous extract of $N$. nucifera against $S$. aureus, P. aeruginosa and C. albicans

The antibacterial activity of different concentrations of ethanol and aqueous extracts of $C$. fistula is represented in Table 1. The results indicated that the plant extracts showed antibacterial activity at variable degrees against $S$. aureus and $P$. aeruginosa. The highest antibacterial activity was exerted at $1000 \mathrm{mg} / \mathrm{ml}$ of both extracts against $S$. aureus and $P$. aeruginosa,. However, both extracts did not show antifungal activity against $C$. albicans. Both extracts showed moderate antibacterial activity against $P$. aeruginosa at the concentrations of 500 and $1000 \mathrm{mg} / \mathrm{ml}$. When consider the both extracts, the ethanol extract of leaves of C. fistula at $1000 \mathrm{mg} / \mathrm{ml}$ showed the highest activity against $S$. aureus.

\subsection{Determination of the zones of inhibition of different concentrations of white flower extracts of $N$. nucifera against selected microorganisms}

The antibacterial activity of different concentrations of ethanol and aqueous extracts of $N$. nucifera flowers is represented in Table 2. The results indicated that the different concentrations of aqueous extract of white flower of $N$. nucifera showed antimicrobial activity at variable degrees against all three selected organisms. The extract showed the highest antimicrobial activity against $S$. aureus. However, different concentrations of ethanol extract of white flowers of $N$. nucifera showed antimicrobial activity against $S$. aureus and $P$. aeruginosa except for $C$. albicans. When consider the both extracts, the aqueous extract of the white flower of $N$. nucifera showed the highest activity against $S$. aureus.

\subsection{Determination of the zones of inhibition of different concentrations of leaf extracts of $A$. indica against selected microorganisms}

The antimicrobial activity of different concentrations of ethanol and aqueous extracts of $A$. indica leaves is represented in Table 3. The results indicated that the ethanol and aqueous extracts of $A$. indica leaves showed antibacterial activity against $S$. aureus only. All 
the tested concentrations of both extracts were exhibited antibacterial activity against $S$. aureus and the aqueous extract showed the highest activity against $S$. aureus. Furthermore, both extracts did not show antifungal activity against $C$. albicans.

\subsection{Determination of the effective extract of each plant and effective concentration of selected plant extracts against tested microorganisms to formulate a combined extract}

Ethanol and aqueous extracts of all three plants of $C$. fistula, A. indica and $N$. nucifera at concentrations ranging from $62.5-1000 \mathrm{mg} / \mathrm{ml}$ exhibited maximum antimicrobial activity against $S$. aureus with zones of inhibition ranging from 7.0 to $21.0 \mathrm{~mm}$. Hence, the half-maximal inhibitory concentration $\left(\mathrm{IC}_{50}\right)$ values of ethanol and aqueous extracts of all three plants of C. fistula, A. indica and N. nucifera were determined against $S$. aureus.

Figure 1 shows the $\mathrm{IC}_{50}$ values of ethanol and aqueous extracts of $C$. fistula, A. indica and $N$. nucifera against $S$. aureus. The values of $\mathrm{IC}_{50}$ of ethanol extracts of C. fistula, A. indica and N. nucifera were $87 \mathrm{mg} / \mathrm{ml}$, $119.9 \mathrm{mg} / \mathrm{ml}$ and $221 \mathrm{mg} / \mathrm{ml}$ respectively. The value of $\mathrm{IC}_{50}$ of aqueous extract of $C$. fistula was $166 \mathrm{mg} / \mathrm{ml}$. The values of $\mathrm{IC}_{50}$ of aqueous extracts of both plants of $A$. indica and $N$. nucifera were determined as $87 \mathrm{mg} / \mathrm{ml}$. Since the ethanol extract of $C$. fistula and the aqueous extracts of $A$. indica and $N$. nucifera were demonstrated the maximum inhibition effect, these extracts were selected as the suitable extracts to incorporate into the combined extract.

Effective concentrations of ethanol extract of $C$. fistula, aqueous extract of $A$. indica and aqueous extract of $N$. nucifera were determined against the tested microorganisms. Figure 2 represents the dose-response curves of the ethanol extract of $C$. fistula, aqueous extract of $A$. indica and aqueous extract of $N$. nucifera against tested microorganisms.

According to the dose-response curve of the ethanol extract of $C$. fistula, the effective concentration ranges for $S$. aureus and P. aerogenosa were 30-257 $\mathrm{mg} / \mathrm{ml}$ and $173-933 \mathrm{mg} / \mathrm{ml}$ respectively. Hence, the final effective concentration of ethanol extract of $C$. fistula was selected as $250 \mathrm{mg} / \mathrm{ml}$ for both microorganisms. Effective concentration range of aqueous extract of A. indica for S. aureus was range from $47.44 \mathrm{mg} / \mathrm{ml}$ to $1233.00 \mathrm{mg} / \mathrm{ml}$. Hence $1000 \mathrm{mg} / \mathrm{ml}$ was selected as the effective concentration of aqueous extract of $A$. indica for $S$. aureus. By considering the dose-response curves of aqueous extract of $N$. nucifera, the effective concentration ranges for $S$. aureus, $P$. aerogenosa and $C$. albicans were $35-281 \mathrm{mg} / \mathrm{ml}, 36-309 \mathrm{mg} / \mathrm{ml}$ and $170-776$ $\mathrm{mg} / \mathrm{ml}$. Hence, $250 \mathrm{mg} / \mathrm{ml}$ was selected as the effective concentration of aqueous extract of $N$. nucifera for $S$. aureus, $P$. aerogenosa and C. albicans.

According to the effective concentrations selected from each extract, the proportions of the extract in the combination that incorporated into herbal soap were determined as follows.
C. fistula
$250 \mathrm{mg} / \mathrm{ml}$
: N. nucifera
: $250 \mathrm{mg} / \mathrm{ml}$
: A. indica
: $1000 \mathrm{mg} / \mathrm{ml}$

\subsection{Determination of the antimicrobial activity of the combined plant extract and formulated herbal soap}

Table 4 represents the antimicrobial activity of the combined plant extract. Combined extract showed the highest activity against $S$. aureus. Combined extract showed enhanced activity compared to individual extracts against the tested microorganisms.

The antimicrobial activity of the formulated herbal soap was investigated using the agar well diffusion method. Figure 3 and Table 5 represents the diameter of the zone of inhibition for $S$. aureus, $P$. aeruginosa and $C$. albicans at different concentrations of herbal soap. The diameter of the zone of inhibition exhibited by gentamycin for $S$. aureus and $P$. aeruginosa were $31.0 \pm 0.5 \mathrm{~mm}$ and $30 \pm 0.4 \mathrm{~mm}$ respectively and of clotrimazole for C. albicans was $26.0 \pm 0.4 \mathrm{~mm}$.

The extracts that exhibited maximal activity were ethanol extract of $C$. fistula and the aqueous extracts of A. indica and N. nucifera. Ethanol extract of $C$. fistula exhibited zones of inhibition ranging from 9.0 to $21.0 \mathrm{~mm}$ and 8.0 to $10.0 \mathrm{~mm}$ against $S$. aureus and $P$. aeruginosa respectively. Aqueous extract of $A$. indica exhibited zones of inhibition ranging from 9.0 to 21.0 $\mathrm{mm}$ against $S$. aureus whereas aqueous extract of $N$. nucifera exhibited zones of inhibition ranging from 7.0 to $20.0 \mathrm{~mm}, 7.0$ to $10.0 \mathrm{~mm}$ and 7.0 to $10.0 \mathrm{~mm}$ against $S$. aureus, $P$. aeruginosa and $C$. albicans respectively. According to the Table 5, formulated herbal soap exhibited zones of inhibition ranging from 15.0 to 28.0 $\mathrm{mm}, 15.0$ to $25.0 \mathrm{~mm}$ and 15.0 to 25.0 against $S$. aureus, $P$. aeruginosa and $C$. albicans respectively at a similar range of concentrations. Hence, the formulated herbal soap showed enhanced antimicrobial activity compared to individual extracts.

\subsection{Evaluation of physical and chemical parameters of formulated soap}

The physical and chemical parameters of the formulated herbal soap were determined. Parameters such as color, odor, appearance, $\mathrm{pH}$, etc. were tested. Table 6 represents the physical and chemical parameters of the formulated soap. The formulation exhibited good appearance characteristics as well as the $\mathrm{pH}$ was 9.1. Other parameters such as percentage free alkali, foam height, foam retention, alcohol insoluble matter and percentage of moisture were determined. 
Table 4. Diameters of zone of inhibition of combined extract for selected microorganisms.

\begin{tabular}{lccc}
\hline Microorganism & $\begin{array}{l}\text { The diameter of the zone of } \\
\text { inhibition of combined extract } \\
(\mathbf{m m})\end{array}$ & $\begin{array}{l}\text { The diameter of the zone of } \\
\text { inhibition for the positive } \\
\text { control }(\mathbf{m m})\end{array}$ & $\begin{array}{l}\text { The diameter of the zone of } \\
\text { inhibition for negative control } \\
(\mathbf{m m})\end{array}$ \\
\hline S. aureus & $30.0 \pm 1.0$ & $37.0 \pm 1.0$ & $00.0 \pm 0.0$ \\
$\boldsymbol{P}$. aeruginosa & $26.0 \pm 1.0$ & $32.0 \pm 1.0$ & $0.0 \pm 0.00$ \\
C. albicans & $16.0 \pm 1.0$ & $25.0 \pm 1.0$ & $0.0 \pm 0.00$ \\
\hline
\end{tabular}

Data presented as Mean \pm SD

Table 5. Diameters of zone of inhibition of formulated soap for selected microorganisms.

\begin{tabular}{lccc}
\hline Concentration $(\mathbf{m g} / \mathbf{m l})$ & \multicolumn{2}{c}{ The diameter of zone of inhibition $(\mathbf{m m})$ of formulated herbal soap } \\
\cline { 2 - 4 } & S. aureus & P. aeruginosa & \multicolumn{2}{c}{ albicans } \\
\hline $\mathbf{1 0 0 0}$ & $28.0 \pm 0.5^{*}$ & $25.0 \pm 0.4^{*}$ & $25.0 \pm 0.4^{*}$ \\
$\mathbf{5 0 0}$ & $24.0 \pm 0.5^{*}$ & $23.0 \pm 0.4^{*}$ & $25.0 \pm 0.4^{*}$ \\
$\mathbf{2 5 0}$ & $22.0 \pm 0.5^{*}$ & $20.0 \pm 0.4^{*}$ & $20.0 \pm 0.4^{*}$ \\
$\mathbf{1 2 5}$ & $20.0 \pm 0.5^{*}$ & $19.0 \pm 0.4^{*}$ & $19.0 \pm 0.4^{*}$ \\
$\mathbf{6 2 . 5}$ & $18.0 \pm 0.5^{*}$ & $17.0 \pm 0.4^{*}$ & $18.0 \pm 0.4^{*}$ \\
$\mathbf{3 1 . 2 5}$ & $15.0 \pm 0.5^{*}$ & $15.0 \pm 0.4^{*}$ & $15.0 \pm 0.4^{*}$ \\
Positive control & $31.0 \pm 0.5^{*}$ & $30.0 \pm 0.4^{*}$ & $26.0 \pm 0.4^{*}$ \\
Negative control & $0.0 \pm 0.0$ & $0.0 \pm 0.0$ & $0.0 \pm 0.0$ \\
\hline
\end{tabular}

Data presented as Mean \pm SD

*Significant when compared with the negative control; $p<0.05$

Table 6. Physical and chemical parameters of the formulated herbal soap.

\begin{tabular}{llccccccc}
\hline Color & Odour & Appearance & pH & $\begin{array}{l}\text { \% free } \\
\text { alkali }\end{array}$ & $\begin{array}{l}\text { Foam height } \\
(\mathbf{c m})\end{array}$ & $\begin{array}{l}\text { Foam } \\
\text { retention } \\
(\mathbf{m i n})\end{array}$ & $\begin{array}{l}\text { Alcohol } \\
\text { insoluble } \\
\text { matter }(\%)\end{array}$ & $\begin{array}{l}\text { Moisture/Volatile } \\
\text { Matter }(\%)\end{array}$ \\
\hline $\begin{array}{l}\text { Dark } \\
\text { brown }\end{array}$ & Fragrant & Good & 9.11 & 1.6 & 9.5 & 7 & 24.6 & 15.85 \\
\hline
\end{tabular}

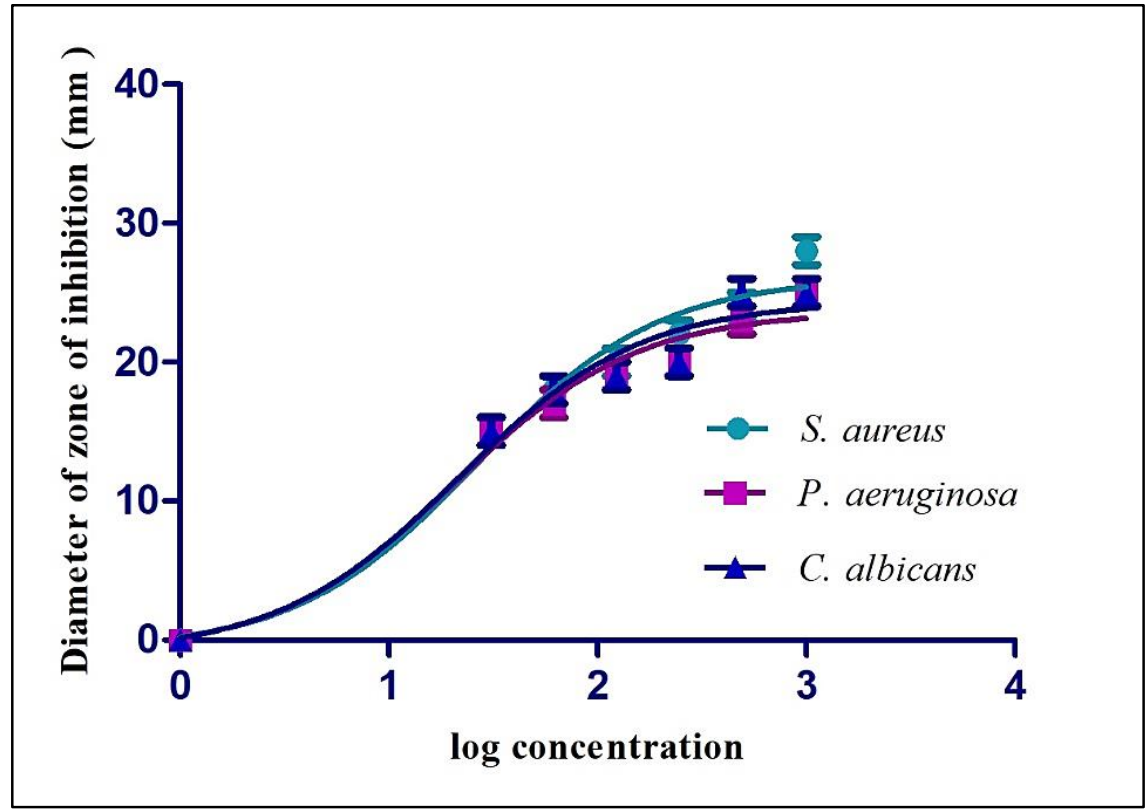

Figure 3. Dose-response curve for formulated soap against $S$. aureus, $P$. aeruginosa and C. albicans.

\section{DISCUSSION}

Herbal soaps are products which are incorporated various plant extracts into the soap base. Nowadays, herbal soaps are gaining much attention due to the various advantages over synthetic soaps. Synthetic ingredients and artificial colors that are incorporated in soaps may lead to skin irritations.
Vast arrays of plants have the potential for antimicrobial activity. Mahato and Sharma ${ }^{23}$ have reviewed and summarized the antimicrobial properties of some medicinal plants.

The present study has formulated a herbal soap using the extracts of $C$. fistula, A. indica and $N$. nucifera and the antimicrobial activity of the individual extracts, the combined extract and the herbal soap was evaluated 
against the common microorganisms. Furthermore, the physicochemical parameters of the herbal soap were evaluated. Local availability and feasibility were considered in selecting plants possessing antimicrobial activity.

According to the literature, aqueous extract of leaves of $A$. Indica has shown antimicrobial activity against human pathogenic bacteria (S. aureus, Enterococcus feacalis, Proteus mirabilis and $P$. aeuroginosa) and fungi (Aspergillus fumigatus and C. albicans) ${ }^{20}$. Hydro-alcohol extract of white flowers $N$. nucifera has shown antimicrobial activity against $S$. aureus, $P$. aeruginosa, Escherichia coli, Klebsiella pneumonia, Bacillus subtilis and A. niger ${ }^{21}$. Hydro-alcohol extracts of the leaves of $C$. fistula possessed antimicrobial activity against human pathogenic bacteria (S. aureus, Streptococcus pyogenes, E. coli, P. aeruginosa) and fungi (A. niger, A. clavatus and C. albicans $)^{24}$. C. fistula, $A$. indica and $N$. nucifera are considered as important herbs used in various traditional systems of medicine and all parts of the plants are used in traditional medicine. The selected plants are used in the treatment of skin diseases, worm and microbial infections, treatment of wounds, sores and ulcers etc $c^{8,10,11,18}$.

Selected plant extracts in the present study possessed antibacterial activity against both Gram-positive and Gram-negative bacterial isolates and antifungal activity against fungal isolates.

To establish the previous findings on Sri Lankan plants, we have evaluated the antimicrobial activity of aqueous and ethanolic extracts of leaves of $A$. indica, white flowers of $N$. nucifera and leaves of $C$. fistula against $S$. aureus (Gram-positive), $P$. aeruginosa (Gram-negative) and C. albicans (fungi). Further the findings of the study supported traditional claims in the literature.

Very few studies were reported about the formulation of herbal soaps and evaluating their antimicrobial activity. Polyherbal soap formulation prepared using coconut oil, castor oil, neem oil, mentha oil and rose petal extracts has exhibited antimicrobial activity against $E$. $\operatorname{coli}^{25}$. Afsar and Khanam, has formulated a herbal soap incorporating extracts of $C$. fistula, Milletia pinnata and Ficus religiosa and the antimicrobial activity was evaluated against $E$. coli (MTCC-1698), S. aureus (MTCC1143) and P. aeruginosa (MTCC-2453) ${ }^{22}$. However, there are no any formulations based on combined extracts of C. fistula, A. indica and N. nucifera found in literature.

Authenticated plants were collected and basic operations such as pre-washing, drying and grinding were done to obtain a homogenous sample to facilitate extraction. Aqueous and ethanol extracts of selected medicinal plants were evaluated for antimicrobial activity by agar well diffusion method. According to the findings of the present study, aqueous and ethanol extracts of leaves of $C$.fistula have exhibited growth inhibition against $S$. aureus and $P$. aeruginosa. A similar type of finding was observed in the study conducted by Bhalodia and Shukla ${ }^{24}$. However, there was a growth inhibition against $C$. albicans by hydroalcoholic extract of leaves of $C$. fistula in the study conducted by Bhalodia and Shukla ${ }^{24}$ whereas no antifungal activity was detected in the present study against $C$. albicans by both aqueous and ethanol extracts of leaves of $C$. fistula.

Even though Reddy et $\mathrm{al}^{20}$. have confirmed the antimicrobial activity of aqueous extract of leaves of $A$. indica against $S$. aureus, $P$. aeuroginosa and $C$. albicans, the present study did not show any growth inhibition against $P$. aeruginosa and $C$. albicans.

A limited literature was available on the antimicrobial activity of the white flower of $N$. nucifera. According to the literature hydroethanolic extract of $N$. nucifera white flowers showed antimicrobial activity against $S$. aureus and $P$. aeruginos $a^{21}$.In this study, the aqueous extract of $N$. nucifera white flower has exhibited antimicrobial activity against $S$. aureus, $P$. aeruginosa and C. albicans. However, Brindha and $\mathrm{Arthi}^{21}$ have not evaluated the antifungal activity against $C$. albicans.

When considering the antimicrobial activity of individual plant extracts of this study, the highest activity was detected against $S$. aureus, mild and poor activities were detected against $P$. aeruginosa and $C$. albicans respectively.

Antimicrobial activity was characterized by the $\mathrm{IC}_{50}$ value. The $\mathrm{IC}_{50}$ is used to assess and compare the effectiveness of inhibitory compounds ${ }^{26}$. Ethanol or aqueous extract of each plant was selected to formulate the combined extract. The most effective extract of each plant was selected by comparing the $\mathrm{IC}_{50}$ values obtained from the log dose vs the response curve of each extract against $S$. aureus. Bhat et al., ${ }^{27}$ have used $\mathrm{IC}_{50}$ values to determine the antimicrobial effectiveness of different extracts of Acacia powder. Ethanol extract of C. fistula, aqueous extracts of $A$. indica and $N$. nucifera were selected based on $\mathrm{IC}_{50}$ values against $S$. aureus to incorporate into the soap formulation.

From all three types of plant extracts selected, a combination of extract was formulated. Proportions of each extract in the combination were determined by using the log dose vs. response curve for each extract considering all three organisms. (Concentration that lies within the range for all organisms was selected). Combined extract was included with all three extracts at a ratio of 1:1:4 (C. fistula: $N$. nucifera: $A$. indica).

In this study, the antimicrobial activity of the combined extract was determined. Results gained for the growth inhibition (diameter of the zone of inhibition) were comparatively higher than the results of individual extracts against the $S$. aureus, $C$. albicans and $P$. arugenosa. Enhanced antimicrobial activity of the combined plant extract in the present study can be attributed to the synergistic effect produced after the combination of 
individual extracts. A similar phenomenon has been discovered by other scientists by combining different plant extracts ${ }^{28,29}$. However, there was no reported literature on the combination of selected extracts of C. fistula, A. indica and N. nucifera and evaluation of its antimicrobial activity.

Antimicrobial herbal soap was formulated considering its microbiological, physical and chemical properties. The selected herbal extracts as active ingredients and several additives have been incorporated into the glycerin soap base which has been used as the vehicle for the formulation. Herbal soaps in $50 \mathrm{~g}$ in weight were formed by adding plant extracts, distilled water, stearic acid and natural volatile oil into the glycerin soap base. However, the active ingredients and added excipients should be compatible with the vehicle ${ }^{30}$.

Physicochemical characteristics of soap include moisture content, total fat matter, $\mathrm{pH}$, free caustic alkalinity and percentage chloride. These characteristics depend mainly on the strength and purity of alkali, the kind of oil used and the completeness of saponification ${ }^{31}$. Appearance, color and odour were observed as physical properties of the final product. The dark brown color of the soap arises due to the plant extractions. Most of the herbal soaps exhibit a brown color due to the dominant color coming from various plant extracts ${ }^{33}$. Fragrant odor was the result of adding the natural volatile oil of N. nucifera.

Healthy skin has a $\mathrm{pH}$ range of 4 to $6^{32}$. The $\mathrm{pH}$ of the skin products is expected to maintain closer to this range as much as possible to reduce irritation ${ }^{33}$. As soap is alkaline $(\mathrm{pH} \sim 10)$ in an aqueous solution because the soap base is the salt of a weak acid (fatty acid) and strong base $(\mathrm{NaOH})$. The alkalinity favours detergency ${ }^{34}$. The $\mathrm{pH}$ of the formulated herbal soap at $28^{\circ} \mathrm{C}$ was 9.11 . According to the SLS 1220 standard (Sri Lanka accreditation board for conformity assessment), the $\mathrm{pH}$ of the soap should be in the range of 4-10. The $\mathrm{pH}$ of the formulated soap was in an acceptable range and safe to use. The $\mathrm{pH}$ of a soap prepared from A. indica seed oil was $10.4^{34}$ and the $\mathrm{pH}$ of a herbal soap formulated incorporating extracts of $C$. fistula, Milletia pinnata and Ficus religiosa was reported as $7.0^{27}$. The increased $\mathrm{pH}$ of the soap produces a significant increase in microbial growth ${ }^{35}$. Korting et al. examined the effect of different skin cleansing methods in healthy individuals aiming on the density of bacterial flora and the $\mathrm{pH}$ of the skin surface. After soap washing, the count of propionibacteria elevated strongly and dropped after application of syndet which is more acidic in nature ${ }^{36}$.

The total alkali means the presence of total alkaline components in the finished soap. The value of free caustic alkali measures the abrasiveness of any given soap. Free caustic alkali results from improper or incomplete saponification. High free alkali amount makes the soap more abrasive and it may cause harm to the $\operatorname{skin}^{37}$.
The herbal soap incorporated seed oil of A. indica reported $0.06 \%$ of free alkali ${ }^{38}$, whereas the said value of a herbal soap formulated incorporating extracts of C. fistula was $0.27 \%^{17}$. The free caustic alkali amount of the formulated herbal soap under this study was $1.6 \%$ which is much higher than the reported values. However, according to SLS 1220, the percentage of free alkali should be higher than $0.006 \% .0 .05 \%$ is the maximum amount declared by ISO standards ${ }^{39}$. Therefore, the soap does not comply with the ISO standards regarding the percentage of free alkali.

One of the parameters that use to detect the purity of the soap is matter insoluble in alcohol (MIA). This parameter is used to determine the non-soap ingredients known as builders or fillers such as sodium carbonate, sodium silicate and minor compounds such as whitening agents, bleachers in the final product ${ }^{40}$. The additives and foreign matter are known as ethanolinsoluble matter in soap. Additive/s is not a part of soap and includes colour additives, fragrance, herbs, silicon dioxide, etc. Inorganic matter such as carbonates, borates, perborates, chlorides and organic matter such as starches, dextrins, caseins, sugars, cellulose derivatives consider as foreign matter in soap. Main principle based for MIA is that separation of builders from active detergent and that is achieved by the use of alcohol. The standard procedure for analyzing commercial synthetic detergents consists in the separation of alcohol-soluble and insoluble fractions by extraction with ethanol ${ }^{37}$. The higher MIA value indicates that it contains a high level of impurities which may cause the level of impurities of alkali used for the soap ${ }^{31}$. The standard percentage of the MIA range is between $36-77 \%{ }^{41}$. The value of MIA for formulated herbal soap was $24 \%$ and it was in an acceptable range. However, the herbal soap formulated by Afsar and Khanam $^{22}$, incorporating extracts of C. fistula was $18 \%$.

Moisture content is the major factor affecting the deterioration of formulated soap. It is a parameter that measures the shelf life. High moisture content leads to the hydrolysis of soap on storage and facilitates microbial growth ${ }^{33}$. The standard range for the moisture content is between $10-20 \%{ }^{41}$. Moisture content of the formulated soap was $15.85 \%$ which falls in the acceptable range. Therefore, it has the potential to prevent deterioration that causes due to high moisture content. The herbal soap incorporating seed oil of $A$. indica reported $12.6 \%$ of moisture content ${ }^{34}$, which is lower than the product formulated under this study.

Another important physicochemical characteristic is the percentage chloride levels. Excess chloride levels may cause soaps to $\mathrm{crack}^{34}$. However, the percentage of chloride levels was not determined under this study.

Glycerin is the most effective humectant available to increase stratum corneum hydration ${ }^{42}$. Soap base used in the present study was composed of glycerin which promotes the moisturizing ability of the skin. This is a 
potential benefit when using the soap product.

Varying time was observed for foam retention or foam stability. Herbal soap prepared with $C$. fistula reported 6 minutes of foam retention ${ }^{22}$, whereas the time observed under this study was 7 minutes. Even though both formulations were used glycerin soap base, the observed time for foam retention was different. This variation of foam retention time depends on the different concentrations of ingredients used in the soap base formulations ${ }^{33}$. Polyherbal soap formulation prepared using coconut oil, castor oil, neem oil, mentha oil and rose petals extract demonstrated 10 minutes of foam retention time ${ }^{25}$. The lather producing ability of the herbal soap prepared by Sindhu et al. ${ }^{25}$ was more stable than the said ability of the soap prepared in this study.

\section{CONCLUSIONS}

Antimicrobial activity of aqueous and ethanol extracts of A. indica, $N$. nucifera, and $C$. fistula was assessed against S. aureus, P. aeruginosa and C. albicans. Enhanced antimicrobial activity was observed by the combined extract formulated from ethanol extract of C. fistula and aqueous extracts of $A$. indica, and $N$. nucifera and formulated herbal soap when compared to the individual plant extracts. The physical and chemical parameters of the formulated herbal soap were within the accepted range. In conclusion, combined extract has the potential in formulating herbal antimicrobial soaps. Further standardization and assessment of safety of formulated herbal soap would be beneficial in the commercialization of this product.

\section{ACKNOWLEDGEMENT}

The authors acknowledge the Department of Pharmacy and Pharmaceutical Sciences and Department of Medical Laboratory Sciences, Faculty of Allied Health Sciences, University of Sri Jayewardenepura, and Industrial Technology Institute Sri Lanka, for providing the necessary facilities to carry out the study.

\section{Conflict of interest}

The authors report no declaration of interest.

\section{Funding}

None to declare.

\section{Ethics approval}

None to declare.

\section{Article info:}

Received March 4, 2021

Received in revised form April 29, 2021

Accepted May 13, 2021

\section{REFERENCES}

1. Akbar S. A Comprehensive Review of Their Traditional Medical Uses and Scientific Justifications. Handbook of 200 Medicinal Plants. Cham: Springer; 2020.

2. Iwu MW, Duncan AR, Okunji CO. New Antimicrobials of Plant Origin. In: Janick J, Eds. Perspectives on New Crops and New Uses. Alexandria, VA, USA: ASHS Press; 1999. p. 457-62.

3. Jain C, Khatana S, Vijayvergia R. Bioactivity of secondary metabolites of various plants: a review. Int J Pharm Sci Res. 2019;10(2):494-504.

4. Hewage CM, Bandara BMR, Karunaratne V, Wannigama GP, Pinto MRM, Wijesundara DSA. Antibacterial activity of some medicinal plants of Sri Lanka. J Natl Sci Found. 1998;26(1): 27-34.

5. Ariffin NHM, Hasham R. Potential dermatological application on Asian plants. Biotechnol Bioprocess Eng. 2016;21(3):337-54.

6. Rahmani AH. Cassia fistula Linn: Potential candidate in the health management. Pharmacogn Res. 2015;7(3):217-24.

7. Sharma A, Kumar A, Jaitak V. Pharmacological and chemical potential of Cassia fistula L-a critical review. J Herb Med. 2021; 26:100407.

8. Satyavati GV, Raina MK, Sharma M. Medicinal plants of India, Volume 1. New Delhi: Indian Council of Medical Research; 1987.

9. The Ayurvedic Pharmacopoeia of India. Part I, Volume 1. New Delhi: Government of India, Ministry of Health and Family Welfare, Department of Indian Systems of Medicine \& Homeopathy; 2001.

10. Jayaweera DMA. Medicinal Plants (Indigenous and Exotic) used in Ceylon. Colombo: National Science Council of Sri Lanka; 1980.

11. Ayurveda Pharmacopoeia, part III, Volume 1. Sri Lanka: Department of Ayurveda. p. 49-237.

12. Rahmani A, Almatroudi A, Alrumaihi F, Khan A. Pharmacological and therapeutic potential of neem (Azadirachta indica). Pharmacogn Rev. 2018;12(24):250-5.

13. Alzohairy MA. Therapeutics role of Azadirachta indica (Neem) and their active constituents in disease prevention and treatment. Evid Based Complement Alternat Med. 2016;11:1-11.

14. Herrera-Calderon O, Ejaz K, Wajid M, Shehzad M, Tinco-Jayo JA, Enciso-Roca E, et al. Azadirachta indica: Antibacterial activity of neem against different strains of bacteria and their active constituents as preventive in various diseases. Pharmacogn J. 2019;11(6):1597-604.

15. Sharma PC, Yelne MB, Dennis TJ. Database on medicinal plants used in Ayurveda. New Delhi: CCRAS; 2005;3.

16. Bisset NG. Pakistan Encyclopaedia Planta Medica. In: Atta-urRahman, Hakim Mohammed Said, Viqar Uddin ahmad, Eds. Abelmoschus esculentus-Allium sativum, Volume 1. Nazimabad, Karachi Pakistan: Hamdard Foundation Press; 1986.

17. Anonymous. The Wealth of India, A Dictionary of Indian Raw Materials and Industrial products. New Delhi, India: Council of Scientific and Industrial Research; 1948.

18. Gunawardana SLA, Jayasuriya WJABN. Medicinally important herbal flowers in Sri Lanka. Evid Based Complement Alternat Med. 2019;1-18.

19. Wakkumbura HP, Wickramaarachchi WMD, Arawwawala LDAM, Liyanage JA, Rajapakse RPVJ. Assessment of the quality and evaluation of the antioxidant potential of a novel Sri Lankan Ayurvedic polyherbal formulation. Evid Based Complement Alternat Med. 2020;4:1-7.

20. Reddy YRR, Kumari CK, Lokanatha O, Mamatha S, Reddy D. Antimicrobial activity of Azadirachta Indica (neem) leaf, bark and seed extracts. Int J Res Phytochem Pharmacol. 2013;3(1):1-4.

21. Brindha D, Arthi D. Antimicrobial activity of white and pink Nelumbo nucifera gaertn flowers. Asian J Pharm Res Health Care. 2010;2(2):147-55.

22. Afsar Z, Khanam S. Formulation and evaluation of poly herbal 
soap and hand sanitizer. Int Res J Pharm. 2016;7(8):54-7.

23. Mahato TK, Sharma K. Study of medicinal herbs and its antibacterial activity: A review. J Drug Deliv Ther. 2018;8(5-s):47-54.

24. Bhalodia NR, Shukla VJ. Antibacterial and antifungal activities from leaf extracts of Cassia fistula 1.: An ethnomedicinal plant. J Adv Pharm Technol Res. 2011;2(2):104-9.

25. Sindhu RK, Chitkara M, Kaur G, Kaur A, Arora S, Sandhu IS. Formulation development and antimicrobial evaluation of polyherbal soap. Plant Arch. 2019;19(2):1342-6.

26. Soothill JS, Ward R, Girling AJ. The IC50: an exactly defined measure of antibiotic sensitivity. J Antimicrob Chemother. 1992;29(2):137-9.

27. Bhat IH, Lee MY, Khanam Z. A preliminary study on antibacterial potential, minimal inhibitory concentration (MIC), half maximal inhibitory (IC50) concentration of methanolic extract of Acacia powder. In: International Conference on Chemistry and Environmental Sciences Research; Pinang, Malaysia; 2014. p. 73-81.

28. Islam R, Rahman MS, Hossain R, Nahar N, Hossin B, Ahad A, et al. Antibacterial activity of combined medicinal plants extracts against multiple drug-resistant strains. Asian Pac J Trop Dis. 2015;5(Sup 1):S151-4.

29. Biqiku L, Lupidi G, Petrelli D, Vitali LA. Antimicrobial activity of single and combined extracts of medicinal plants from Cameroon. J Pharm Biol Sci. 2016;11(4):86-90.

30. Garg T, Rath G, Goyal A. Comprehensive review on additives of topical dosage forms for drug delivery. Drug Deliv. 2014; 22(8):969-87.

31. Vivian OP, Nathan O, Osano A, Mesopirr L, Omwoyo WN. Assessment of the physicochemical properties of selected commercial soaps manufactured and sold in Kenya. Open J Appl Sci. 2014;4(8):433-40.

32. Ali SM, Yosipovitch G. Skin pH: from basic science to basic skin care. Acta Derm Venereol. 2013;93(3):261-7.
33. Akuaden NJ, Chindo IY, Ogboji J. Formulation, physicochemical and antifungal evaluation of herbal soaps of Azadiracta Indica and Ziziphus mauritiana. IOSR J Appl Chem. 2019;12(8): 26-34.

34. Mak-Mensah EE, Firempong CK. Chemical characteristics of toilet soap prepared from neem (Azadirachta indica A. Juss) seed oil. Asian J Plant Sci Res. 2011;1(4)1-7.

35. Wiegand C, Abel M, Ruth P, Elsner P, Hipler UC. pH influence on antibacterial efficacy of common antiseptic substances. Skin Pharmacol Physiol. 2015;28(3):147-58.

36. Korting HC, Kober M, Mueller M, Braun-Falco O. Influence of repeated washings with soap and synthetic detergents on $\mathrm{pH}$ and resident flora of the skin of forehead and forearm. Results of a cross-over trial in health probationers. Acta derm Venereol. 1987;67(1):41-7.

37. Berkowitz D, Bernstein R. Analysis of Soap-Synthetic Detergent Mixtures in Bar Form. Ind Eng Chem Anal Ed. 1944;16(4): 239-41.

38. Sabaani NJ, Peñaredondo MAE, Sepe MC. Antibacterial activity of liquid soap with combined Sargassum sp. and Eucheuma sp. seaweed extracts. Aquac Aquar Conserv Legis. 2019;12(5): 1514-23.

39. Anonymous. Bureau of Indian standards, Toilet soap. 2011 IS $2888 ; 2004$.

40. Popescu V, Soceanu A, Dobrinas S, Stanciu G, Epure DT. Quality control and evaluation of certain properties for soaps made in Romania. Scientific study and research: Chemistry and Chemical Engineering, Biotechnology. Food Industry. 2011;12(3): 257-61.

41. Idoko O, Emmanuel SA, Salau AA, Obigwa PA. Quality assessment on some soaps sold in Nigeria. Niger J Technol. 2018; 37(4):1137-40.

42. Chularojanamontri L, Tuchinda P, Kulthanan K, Pongparit K. Moisturizers for acne: What are their constituents. J Clin Aesthet Dermatol. 2014;7(5):36-44. 